\title{
ENDIVIDADO OU POUPADOR: \\ IMPACTO DAS VARIÁVEIS SOCIODEMOGRÁFICAS E DO GERENCIAMENTO FINANCEIRO
}

\author{
INDEBTED OR SAVING:
}

\section{IMPACT OF SOCIODEMOGRAPHIC VARIABLES AND FINANCIAL MANAGEMENT}

\author{
Kelmara Mendes Vieira \\ Docente do Programa de Pós-Graduação em Gestão de Organizações Públicas - Universidade Federal de Santa Maria - UFSM \\ Santa Maria, RS, Brasil \\ E-mail: Kelmara@terra.com.br
}

Rafael Rudolfo Kreutz

Mestrando do curso de Gestão de Organizações Públicas - Universidade Federal de Santa Maria - UFSM

Santa Maria, RS, Brasil

E-mail: rafael.kreutz@gmail.com

\section{RESUMO}

O presente estudo teve por objetivo analisar o impacto do gerenciamento financeiro e das variáveis sociodemográficas na probabilidade de os indivíduos serem "poupadores" ou "endividados". Visando atingir o objetivo proposto, optou-se por realizar um estudo quantitativo de cunho descritivo, através de uma survey. Para tanto, foram aplicados 1.577 instrumentos no RS e estimados dois modelos lineares generalizados com a intensão de analisar a influência destes fatores na propensão dos indivíduos serem poupadores ou endividados. $O$ instrumento de coleta de dados foi estruturado em 34 questões divididas em três blocos. Os principais resultados indicam que com impacto negativo na probabilidade de ser "endividado" destacou-se as variáveis conta poupança, controle de gastos e idade. Enquanto ter cadastro positivo e possuir dependentes impactam positivamente na probabilidade de serem endividados. Para o modelo dos poupadores, identificou-se que ter cadastro negativo, emprestar o nome, ser do gênero feminino, e com escolaridade ensino médio, faculdade e pós-graduação são características que diminuem a probabilidade, e possuir conta poupança, manter controle de gastos e auferir renda acima de 7 mil aumenta a probabilidade de ser poupador.

Palavras-chave: Endividados. Poupadores.

Variáveis sociodemográficas. Gerenciamento Financeiro.

Data de submissão: 10 de agosto de 2017.

\begin{abstract}
The present study aimed to analyze the impact of financial management and sociodemographic variables on the probability of individuals being "savers" or "indebted". Aiming to achieve the proposed objective, a quantitative study of a descriptive nature was chosen through a survey. For that, 1,577 instruments were applied in RS and estimated two generalized linerar models with the intention of analyzing the influence of these factors on the propensity of the individuals to be savers or indebted. The data collection instrument was structured in 34 questions divided into three blocks. The main results indicate that the negative impact on the probability of being "indebted" stood out the variables account savings, control of expenses and age. While having a positive register and having dependents positively impact the probability of being indebted. For the savers model, it has been identified as having a negative register, lending the name, being female, and with high school education, college and post-graduation are characteristics that decrease the probability, and have savings account, keep control of expenses and earning income over 7 thousand increases the likelihood of being a saver.
\end{abstract}

Keywords: Indebted. Savers. Socio-demographic variables. Financial Management. 


\section{INTRODUÇÃO}

No Brasil somente quatro em cada dez consumidores se sentem seguros para gerir e organizar a própria vida financeira [SPC] (2016). Tal situação se agrava na medida em que estudos indicam o aumento do endividamento e inadimplência das famílias brasileiras. Pesquisa da Confederação Nacional do Comércio de Bens, Serviços e Turismo (2016) mostra que 59,6\% dos entrevistados estão endividados, 23,2\% possuem contas em atraso e 8,2\% não terão condições de pagar suas contas [CNC] (2016). Dentre as principais formas de endividamento, destaca-se o cartão de crédito, já que seu uso representa atualmente a principal causa da dívida das famílias ( $77,3 \%$ delas), os carnês $(16,7 \%)$, os financiamentos de carro $(12 \%)$ e os créditos pessoais $(10,8 \%)$ também são instrumentos importantes de endividamento familiar (CNC, 2016).

Por outro lado, observa-se na economia, um grupo de indivíduos, cujo comportamento de poupança predomina. Pesquisa do SPC (2016) indica que a poupança é o produto financeiro mais popular, visto que, $69,5 \%$ dos entrevistados declararam possuir uma conta poupança. As razões para poupar são diversas, e vão desde a necessidade de fazer uma reserva para imprevistos, o desejo de acumular recursos para a compra de um bem (carros, imóveis, etc) ou garantir um futuro melhor para família.

Dentre os fatores que podem impactar na probabilidade de um indivíduo ser um "endividado" ou um "poupador" destacam-se os fatores comportamentais e as variáveis sociodemográficas. No campo dos fatores comportamentais estudos indicam, por exemplo, que a compra compulsiva e o materialismo são antecedentes da dívida no cartão de crédito (VIEIRA, OLIVEIRA e KUNKEL, 2016). Em ambos os grupos um fator comportamental importante é o gerenciamento financeiro. A gestão financeira familiar é um aspecto de extrema complexidade na consolidação de uma estrutura sólida em termos monetários e parte desde os cuidados com questões domiciliares, como vestuário e alimentação, até aspectos como gestão de caixa, gestão do crédito, acumulação de capital, gestão da aposentadoria e planejamento imobiliário (PORTER e GARMAN, 1993). A falta de controle dos gastos e dos juros pagos, ausência de planejamento para imprevistos e falta de conhecimento sobre o valor dos rendimentos mensais são situações que favorecem o endividamento e a inadimplência.

Quanto ao papel das variáveis sociodemográficas o impacto é analisado em uma série de estudos (PLAGNOL, 2011; KEESE e SCHMITZ, 2011; DINIZ, 2014). Em relação ao gênero, por exemplo, têm-se duas concepções distintas. Alguns autores evidenciam as mulheres como mais propensas ao endividamento (CARVALHO e ALVES, 2010; TRINDADE, RIGHI E VIEIRA, 2012; VIEIRA, FLORES, KUNKEL, CAMPARA e PARABONI, 2014), já outros evidenciam os homens (MULLER, 2010; WANG, LU e MALHOTRA, 2011; LUCENA e MARINHO, 2013). Nas variáveis idade e escolaridade, a atitude mais favorável às dívidas é dos indivíduos mais novos e daqueles que possuem menor nível de escolaridade (PONCHIO, 2006; VIEIRA, FLORES e CAMPARA, 2015). Ao avaliar a relação entre a variável estado civil e endividamento, Gathergood (2012), Mendes-Da-Silva, Nakamura e Moraes (2012) e Vieira et al. (2015) observaram que os indivíduos solteiros possuem maior propensão ao endividamento.

Nesta perspectiva, este trabalho pretende responder a seguinte questão de pesquisa: como o gerenciamento financeiro e as variáveis sociodemográficas influenciam na chance de o indivíduo se tornar endividado ou poupador? Assim, tem-se por objetivo principal construir dois modelos para identificação da probabilidade dos indivíduos serem "poupadores" ou "endividados" a partir das questões relativas ao 
gerenciamento financeiro e das suas características sociodemográficas. Para isso utiliza-se um modelo linear generalizado binomial. O uso de um modelo linear generalizado, McCullagh e Nelder, (1989), é mais adequado para este tipo de análise do que o modelo clássico de regressão múltipla, especialmente por não pressupor a normalidade da variável resposta.

Como contribuições, destaca-se a maior compreensão dos fatores determinantes das variáveis sociodemográficas e das questões de gerenciamento financeiro que contribuem para que um indivíduo se torne "endividado" ou "poupador". A importância deste estudo vai além do aspecto financeiro, uma vez que o descontrole financeiro além do desequilíbrio orçamentário do indivíduo ou dos seus familiares leva a implicações de ordem social, psicológica e problemas de saúde. E, ainda, a proliferação de casos de famílias incapazes de cumprir os seus compromissos financeiros gera implicações no cenário econômico do país, especialmente em termos de inadimplência (CNC, 2016, SPC, 2016).

\section{REFERENCIAL TEÓRICO}

\section{Propensão ao Endividamento e Inadimplência}

Dado o cenário econômico atual, pode-se perceber um aumento significativo no nível de endividamento da população (CNC,2016). No entanto, segundo Fernandes e Candico (2014), esse movimento, visto em um primeiro momento como positivo, traz como consequência um efeito colateral que é o aumento do endividamento financeiro. Um dos fatores propensores desse aumento foi o crescente aumento da expansão do crédito nos últimos anos ocasionado principalmente pelo aumento dos prazos e pelo arrefecimento das taxas de juros. Tal panorama trouxe como consequência o atingimento de patamares muito elevados de endividamento para as famílias brasileiras que hoje atinge 58,7\% (CNC,2016). Para Moura (2005), esse fator comportamental da elevação do endividamento acontece porque as pessoas passaram a consumir e firmar obrigações financeiras futuras independentes do seu objetivo ser para satisfazer uma necessidade básica ou supérflua.

A cultura social do consumismo criada no país, que gera à busca incessante para satisfazer as necessidades e desejos, somada a facilidade de acesso ao crédito, leva os indivíduos a assumirem compromissos além de suas capacidades financeiras. Por consequência existe surgimento, a partir daí, de situações de endividamento, sobre-endividamento e inadimplência (FRADE, LOPES, JESUS e FERREIRA, 2008; LUSARDI e TUFANO, 2009; GATHERGOOD, 2012).

Assim, fica evidente a importância e necessidade de que os indivíduos sejam dotados de um conhecimento mínimo financeiro para que consigam gerenciar adequadamente suas finanças, e assim poderem criar planos de poupança, e fazer investimentos estratégicos. Para evitar o endividamento faz-se necessário um equilíbrio entre receitas e despesas, ou seja, é fundamental que as famílias analisem com precisão quais são as suas fontes de renda e quais serão suas prioridades. Dessa forma, é possível evitar que sejam feitos gastos supérfluos em detrimento de despesas com necessidades básicas (CAMPARA, 2016). Para os autores Cenci, Pereira e Barichello (2015) as decisões financeiras particulares tem a capacidade de influenciar o comportamento de toda a economia, e são intimamente ligados a problemas como a inadimplência, endividamento familiar e falta de capacidade de planejamento de longo prazo. 
Compreende- se o endividamento como "o saldo devedor de uma pessoa, sendo ocasionado por uma dívida ou mais do que uma simultaneamente" (SILVA, 2014, p. 9). Para Medeiros, Dantas, Silva e Pereira (2014), uma pessoa pode ser considerada como endividada quando não consegue fazer frente as suas obrigações financeiras, assim como quando apresenta incapacidade de pagamento gerando um atraso na liquidação das mesmas.

Identificar os motivos que levam ao possível endividamento tem sido alvo de discussões científicas. Exemplo disso, é a pesquisa do Branco Central do Brasil (BACEN) (2014), teve como objetivo compreender o processo e as motivações que levam os consumidores à situação de endividamento excessivo e a restrições cadastrais. Os resultados evidenciam que são diversas as motivações para o endividamento excessivo. Dentre as principais causas destacou-se os fatos inesperados como a perda de emprego e renda, doença própria e/ou de familiares, morte do responsável pela maior parte da renda familiar, gravidez não programada, separação conjugal. Há também, a falta de planejamento financeiro levando a compras por impulso, excesso de parcelamento de compras e uso de linhas de crédito de forma impulsiva e descontrolada, além do empréstimo do nome, realizando empréstimos em seu nome para amigos ou familiares ou empréstimo de seu cartão de crédito a terceiros.

No que se refere a questão da gestão financeira, na vida pessoal das famílias, pode-se perceber que a dívida apresenta efeitos bem visíveis. Para Keese e Schmitz (2011), a dívida nas famílias acarreta problemas ligados a saúde, como stress e angústia, uma percepção de baixa capacidade de gestão financeira do dinheiro, um menor sentimento de bem-estar financeiro e emoções negativas. Loiola (2014), corrobora afirmando que as dívidas afetam diretamente no estresse, ou seja, quanto maior o volume de dívidas maior o estresse financeiro. Nessa mesma perspectiva Kunkel, Vieira e Potrich (2015), ratificam essas evidências quando destacam que as pessoas endividadas apresentam um sentimento de menor satisfação quanto a situação financeira presente. Além disso, como consequência sentem-se também menos confiantes em uma situação financeira mais confortável no futuro. Destacam ainda que a presença de dívidas traz como consequência sensações negativas como a tristeza, ansiedade, nervosismo, podendo, inclusive, afetar as relações sociais, profissionais e familiares dos endividados.

A cerca do tema endividamento tem-se verificado a existência de pesquisas que abordam a associação do endividamento com os fatores socioeconômicos e demográficas. No que se refere a questão do gênero, têm-se apresentado na literatura duas concepções distintas. Alguns autores evidenciam que as mulheres têm uma maior propensão para o endividamento (TRINDADE et al., 2012; CARVALHO e ALVES, 2010; VIEIRA et al., 2014), pois segundo os mesmos elas têm uma maior pré-disposição para a aquisição de carnês e são mais vulneráveis e propensas a realização de compras com maior frequência. Já o segundo entendimento demonstra que os homens têm maior propensão para o endividamento por terem o costume de utilizar créditos rotativos com maior frequência e tendem a realizar um volume maior de aplicações em bens materiais. Além disso, também costumam utilizar de uma forma mais frequente e extensiva o cartão de crédito, empréstimos consignados e limites da conta e cheque (FLORES, 2012; WANG et al., 2011; LUCENA E MARINHO, 2013). 
No que tange a idade, Worthy, Jonkman e Blinn-Pike (2010), demonstram em seu estudo que jovens de 18 a 25 anos são mais predispostos a assumir riscos maiores e apresentar menor estabilidade financeira o que pode explicar a maior vulnerabilidade à dívida. Na mesma perspectiva Potrich, Vieira, Coronel e Reisoli (2016), evidenciaram que há uma relação negativa entre idade e endividamento, ou seja, a cada ano de vida diminui a probabilidade da propensão para elevados níveis de endividamento.

Em relação a escolaridade, Flores (2012) identificou nos resultados de sua pesquisa que as pessoas sem alfabetização apresentaram maior propensão para se endividarem. Nessa mesma linha Vieira et al (2015), identificaram que as pessoas que apresentam menores graus de instrução apresentam uma maior propensão para o endividamento. Diferente dessa perspectiva, Miotto (2013), afirma que os consumidores com um nível de instrução mais elevado têm maior conhecimento sobre a opções e oportunidades mais viáveis de empréstimos junto ao mercado financeiro. Logo, possuem acesso a oportunidades que possivelmente uma classe menos instruída não teria conhecimento. Assim, quanto maiores a instrução do indivíduo maior a possibilidade de se endividar.

Levando em consideração a variável estado civil e a propensão para o endividamento, Flores (2012), Gathergood (2012) e Vieira et al. (2015) evidenciaram em seus estudos que os solteiros apresentam maior nível de endividamento e são mais propensos ao endividamento. Vieira et al. (2014) evidenciaram que as que mulheres separadas ou viúvas tem uma maior propensão para se endividarem uma vez que elas necessitam arcar com as despesas da casa e cuidados com os filhos. Considerando a variável número de dependentes, Silva (2011) destaca a existência de uma propensão para maior endividamento conforme o número de filhos. Da mesma forma, Keese (2012), destaca em sua pesquisa a existência da propensão a um maior nível de endividamento para as famílias que apresentam um maior número de filhos e dependentes.

Não menos importante, tem-se a relação da ocupação com a propensão ao endividamento. Segundo Disney e Gathergood (2011), os indivíduos que tiveram menores taxas de emprego apresentam um nível de sobreendividamento mais elevado. Na mesma linha, Flores (2012), destaca que as pessoas que não trabalham são mais propensas a um maior endividamento.

Outro fator que tem ralação com os níveis de endividamento do indivíduo é a renda, a qual, tem influência sobre a forma de consumo das famílias, pois as categorias de despesas têm uma diferente relevância no orçamento familiar em detrimento da progressão da renda. Nessa perspectiva Vieira et al. (2015) e Bricker, Kennickell, Moore e Sabelhaus (2012), ratificam essas evidências quando identificam uma relação de maior propensão para se endividar naquelas famílias que apresentam uma renda mais baixa. Os resultados auferidos evidenciam que esta situação tem como principal motivado as restrições orçamentárias. Por fim, pode-se evidenciar através do estudo de Keese (2010), a existência de relação quanto a situação da residência (própria ou alugada) e a capacidade das famílias para lidar melhor com as dívidas. Na sua visão as famílias que possuem casa própria têm maior capacidade para lidar com as dívidas que as famílias que possuem casa alugada. A seguir apresenta-se no Quadro 1 uma síntese das relações expostas entre as variáveis socioeconômicas e o endividamento. 
Quadro 1- Síntese da relação entre as variáveis socioeconômicas e demográficas e o Endividamento

\begin{tabular}{|c|c|c|}
\hline Variável & Relação esperada & Autores \\
\hline \multirow{2}{*}{ Gênero } & Mulheres são mais propensas ao endividamento. & $\begin{array}{l}\text { Trindade; Righi e Vieira (2012); Carvalho e Alves } \\
\text { (2010); Vieira et al. (2014) }\end{array}$ \\
\hline & Homens são mais propensos ao endividamento. & $\begin{array}{l}\text { Flores (2012); Wang; Lu e Malhotra (2011); Lucena } \\
\text { e Marinho (2013) }\end{array}$ \\
\hline Idade & $\begin{array}{l}\text { Indivíduos mais velhos tendem a possuir menores níveis de } \\
\text { endividamento. }\end{array}$ & $\begin{array}{l}\text { Worthy, Jonkman e Blinn-Pike (2010); Flores } \\
\text { (2012); Potrich et al (2016) }\end{array}$ \\
\hline \multirow{2}{*}{ Escolaridade } & $\begin{array}{l}\text { Indivíduos com menor nível educacional tendem a apresentar } \\
\text { maior propensão ao endividamento. }\end{array}$ & Vieira, Flores e Campara (2015); Flores (2012) \\
\hline & $\begin{array}{l}\text { Indivíduos com maior nível educacional tendem a apresentar } \\
\text { maior propensão ao endividamento. }\end{array}$ & Miotto (2013) \\
\hline \multirow{2}{*}{ Estado Civil } & Indivíduos solteiros possuem maior propensão ao endividamento. & $\begin{array}{l}\text { Gathergood (2012); Vieira, Flores e Campara } \\
\text { (2015); Flores (2012). }\end{array}$ \\
\hline & $\begin{array}{l}\text { Indivíduos separados ou viúvos possuem maior propensão ao } \\
\text { endividamento. }\end{array}$ & Vieira et al. (2014) \\
\hline Dependentes & $\begin{array}{l}\text { Famílias com maior número de dependentes contraem maiores } \\
\text { níveis de endividamento. }\end{array}$ & Keese (2012); Silva (2011) \\
\hline Ocupação & $\begin{array}{l}\text { Indivíduos desempregados possuem maior propensão ao } \\
\text { endividamento. }\end{array}$ & Disney e Gathergood (2011) e Flores (2012) \\
\hline Renda & $\begin{array}{l}\text { Indivíduos com menores níveis de renda apresentam maior } \\
\text { propensão ao endividamento. }\end{array}$ & $\begin{array}{l}\text { Silva (2004); Vieira, Flores e Campara (2015); } \\
\text { Bricker et al. (2012) }\end{array}$ \\
\hline Moradia & $\begin{array}{l}\text { Famílias com casa própria tem maior facilidade para lidar com o } \\
\text { endividamento }\end{array}$ & Keese (2012) \\
\hline
\end{tabular}

Fonte: Desenvolvido pelos autores (2017)

Dada a importância do dinheiro para a maior parte das atividades e aquisições do indivíduo, o mesmo tem uma representatividade bastante significativa e um aspecto essencial na vida das pessoas de um modo geral (SANTOS, 2010). Para tanto, é necessária equidade entre receitas e despesas, tendo as famílias que analisar com precisão quais as suas fontes de renda e quais suas prioridades. Assim, evitando que gastos supérfluos incorram em detrimento de despesas com necessidades básicas da família (CAMPARA, 2016). Dessa forma, torna-se evidente a necessidade da gestão eficiente dos recursos financeiros, ou seja, faz-se necessário que exista um equilíbrio entre as receitas e despesas. Logo, é necessário que as famílias façam uma análise detalhada de suas fontes de receita e com base nisso definam suas prioridades de gastos evitando gastos desnecessários.

Portanto, conclui-se que indivíduos deveriam ser bem informados e educados acerca de questões relacionadas ao gerenciamento de ativos, investimentos, poupança, crédito, entendessem de conceitos básicos subjacentes à gestão dos recursos e soubessem utilizar adequadamente o conhecimento adquirido para planejar e implementar decisões financeiras. Dada sua importância, Mundy (2011), destaca que para que o indivíduo possa ter um comportamento financeiro adequado é necessário que ele desenvolva no mínimo cinco características: honrar com as despesas mensais, ter as finanças sob controle, planejar o futuro, fazer escolhas assertivas de produtos financeiros e manter-se atualizado das questões financeiras. 


\section{MÉTODO}

A metodologia utilizada neste trabalho pode ser classificada como uma pesquisa descritiva, quantitativa e survey. $\mathrm{O}$ método utilizado está dividido em três subitens: $\mathrm{O}$ primeiro apresenta a amostra, o segundo visa descrever o instrumento de pesquisa e o terceiro faz uma breve descrição dos modelos lineares generalizados, técnica de modelagem escolhida para atingir o objetivo do estudo.

\section{Amostra}

A população do estudo compreende as famílias residentes no estado do Rio Grande do Sul, o qual é composto por 497 municípios e possuía uma população total no ano de 2010 de 10.693 .929 habitantes [IBGE] (2010). A amostra foi coletada de maneira a garantir a aplicação nas diferentes mesorregiões e a abranger as metades norte e sul do Rio Grande do Sul. Propôs-se essa segmentação já que o estado do Rio Grande do Sul pode ser dividido, sob a visão econômica, em duas macrorregiões: a metade norte, constituída pela região norte e nordeste do estado que compreendem as zonas da serra e planalto e a metade sul, que compreende a região sul do estado. Segundo a FEE (2013), nas últimas 8 décadas (1940 a 2010), houve grande diferença no Produto Interno Bruto per capita, em que a metade sul apresentou nesse período um déficit per capita médio de 19,13\%, quando comparado a metade norte. A amostra totalizou 1.577 instrumentos aplicados em nove cidades: Agudo, Erechim, Pelotas, Porto Alegre, Restinga Seca, Santa Maria, Santana do Livramento, Santo Ângelo e São Miguel das Missões. Os questionários foram aplicados de forma aleatória, em ambiente externo, entre os meses de outubro 2015 e fevereiro de 2016, por meio de contato com pessoas dispostas a participar.

\section{Instrumento}

O instrumento de coleta de dados foi estruturado em 34 questões divididas em três blocos. O primeiro foi composto por 21 questões (GF1 a GF21) referentes à gestão, decisões, práticas e experiências financeiras pessoais e familiares. A estruturação dessas questões se deu a partir da adaptação de modelos já aplicados por Shockey (2002), OECD (2013) e Brasil (2009), bem como, pela elaboração de questões inéditas por parte dos pesquisadores, vistas como convenientes ao escopo do trabalho. O segundo bloco corresponde à questão principal de pesquisa. A qual é composta por três alternativas que tratam do nível de gastos dos indivíduos. A questão, desenvolvida originalmente por Flores (2012), identifica se os indivíduos gastam menos, igual ou mais do que ganham. Assim, para os fins deste trabalho, os indivíduos que selecionaram a opção "gasto mais do que ganho, são os classificados como "endividados"; já aqueles que assinalaram "gasto menos do ganho", são classificados como "poupadores". Ao passo que os que marcaram "gasto igual ao que ganho" deram origem ao grupo "neutros".

Na última seção do instrumento estão listadas 10 questões (PF1 a PF10) referentes ao perfil: idade, gênero, estado civil, número de dependentes, tipo de moradia, nível de escolaridade, número de pessoas que residem na mesma casa, se trabalham, qual a ocupação, renda mensal familiar. Essa estrutura foi obtida após a execução de três etapas: tradução reversa, avaliação de especialistas e pré-teste. 


\section{Técnica de Análise}

Partindo do pressuposto de que as variáveis binárias, tais como a deste estudo, não são bem descritas por modelos lineares tradicionais, que assumem normalidade, optou-se pelo uso dos modelos lineares generalizados (MLG). Tais modelos, inicialmente propostos por McCullagh e Nelder, (1989), abriram o leque de opções para a distribuição da variável resposta, permitindo que a mesma pertença à família exponencial de distribuições, bem como deram maior flexibilidade para a relação funcional entre a média da variável resposta e o preditor linear (PAULA, 2013). Muitas das distribuições conhecidas pertencem à família exponencial, como, por exemplo, a gama, a poisson, a normal, a normal inversa, a multinomial, e também a binomial, foco deste trabalho.

Um MLG apresenta um componente aleatório associado à distribuição da variável resposta; um componente sistemático linear nos parâmetros, denominado preditor linear ou estrutura linear do modelo; e uma função de ligação, a qual combina o componente aleatório e o componente sistemático. Cordeiro e Demétrio (2007), definem formalmente as condições de utilização de um MLG:

Os modelos lineares generalizados envolvem uma única variável aleatória associada a um conjunto de variáveis explanatórias $x_{1} \ldots, x_{p}$. Para uma amostra de $n$ observações $y_{i}, x_{i}$ para $i=1, \ldots, n$, em que $x_{i}=\left(x_{i 1}, \ldots\right.$, $\left.x_{i p}\right)^{\top}$, é o vetor coluna de variáveis, o MLG envolve os três componentes:

i) Componente aleatório: representado por um conjunto de variáveis aleatórias independentes $Y_{1} \ldots . Y_{1}$ provenientes de uma mesma distribuição que faz parte da família de distribuições exponencial uniparamétrica na forma canônica com parâmetro de perturbação e com médias, $\mu_{1}, \ldots, \mu_{n}$, ou seja,

$$
E\left(Y_{i}\right)=\mu_{i}, i=1, \ldots, n,
$$

sendo $\phi>0$ um parâmetro de dispersão e o parâmetro $\theta_{i}$ denominado parâmetro canônico, a função densidade de probabilidade de yi é dada por:

$$
f\left(y_{i} ; \theta_{i}, \phi\right)=\exp \left\{\phi^{-1}\left[y_{i} \phi_{i}-b\left(\theta_{i}\right)\right]+c\left(y_{i}, \phi\right)\right\},
$$

sendo b(.) e c(.) funções conhecidas.

ii) Componente sistemático: as variáveis explicativas entram na forma de uma soma linear de seus efeitos

$$
\eta_{i}=\sum_{r=1}^{p} x_{i r} \beta_{j}=x_{i}^{T} \beta, \text { ou matricialmente, } \eta=X \beta
$$

sendo $X=\left(x_{1}, \ldots x_{n}\right)^{T}$ a matriz do modelo, $\beta=\left(\beta_{1}, \ldots, \beta_{p}\right)^{T}$ o vetor de parâmetros e $\eta=\left(\eta_{1}, \ldots, \eta_{n}\right)^{T}$ o preditor linear.

iii) Função de ligação: uma função que relaciona o componente aleatório ao componente sistemático, ou seja, relaciona a média ao preditor linear, isto, é,

$$
\eta_{i}=g\left(\mu_{i}\right)
$$

sendo $\mathrm{g}($.$) uma função monótona e duas vezes diferenciável.$ 
Ainda, segundo Cordeiro e Demétrio (2007), a escolha da distribuição é usualmente feita pela natureza dos dados (discreta ou contínua) e pelo seu intervalo de variação (conjunto dos reais, reais positivos ou um intervalo). Neste estudo optou-se pela distribuição bernoulli, devido ao fato da variável assumir apenas os valores 0 e 1. Observa-se que a distribuição binomial pertence à família de distribuições exponencial uniparamétrica na forma canônica e com um parâmetro de perturbação como em (2), atendendo, portanto, ao pressuposto para aplicação de um MLG. As variáveis explanatórias ou covariáveis, entram na forma de uma estrutura linear, constituindo o componente sistemático do modelo. Estas variáveis podem ser de diferentes naturezas e com intervalos de variação diversos, sendo a escolha da matriz de variáveis que irão compor o modelo definidas especialmente a partir da literatura existente sobre os possíveis influenciadores da variável resposta.

A função de ligação é uma função que relaciona o componente aleatório ao componente sistemático, ou seja, relaciona a média ao preditor linear. As funções de ligação de especial interesse nos MLGs são as funções de ligação canônicas. Para a distribuição binomial a ligação canônica é a logística, utilizada neste trabalho. Existem diferentes métodos para a estimação de um MLG, entretanto o método mais utilizado é o da máxima verossimilhança. A estimação por máxima verossimilhança predomina devido ao fato de possuir muitas propriedades ótimas tais como consistência e eficiência assintótica (CORDEIRO e DEMÉTRIO, 2007).

Para avaliação do ajuste do modelo, há uma série de estatísticas e testes a serem aplicados. Dentre as mais utilizadas destacam-se: a função deviance, o resíduo estudentizado, o envelope simulado, o pseudo$\mathrm{R}^{2}$ e o teste RESET (RAMSEY, 1969). Uma das primeiras estatísticas geralmente analisadas é a função desvio (deviance), onde quanto menor o valor do desvio, melhor o ajuste do modelo. Vários tipos de resíduos foram propostos na literatura, como por exemplo, o resíduo ordinal, o estudentizado e o padronizado (COOK EWEISBERG, 1982; ATKINSON, 1985). Dentre os resíduos propostos, um dos mais utilizados é o resíduo estudentizado, devido à vantagem de que o mesmo possui distribuição t-student. Assim, espera-se que os resíduos estudentizados fiquem no intervalo $(-2,2)$. Ainda, para a análise dos resíduos um gráfico importante é o envelope simulado proposto por Atkinson (1985). Esse envelope é tal que sob o modelo correto as quantias (resíduos, alavancagem, distância de Cook, etc) obtidas a partir dos dados observados caem dentro do envelope. Demétrio e Hinde (1997), apresentam um conjunto de macros que permitem fazer esse gráfico para uma grande variedade de modelos.

O pseudo $R^{2}$ de Nagelkerke (1991) é similar ao coeficiente de determinação obtido nos modelos lineares clássicos, já que mostra quanto o modelo explica da variação da variável resposta. Outra alternativa para a avaliação da qualidade do ajuste do modelo é a utilização de critérios de informação. Dentre os principais critérios, um dos mais utilizados é o critério de informação de Akaike (AIC) (AKAIKE, 1974), que é formulado a partir da função log-verossimilhança maximizada. Como critério de decisão tem-se que, dentre dois modelos, o de melhor ajuste será o que apresentar menor AIC. O AIC também pode ser utilizado como critério de seleção de variáveis em procedimentos de estimação via stepwise (HOCKING, 1976).

O teste RESET proposto por Ramsey (1969) é um teste geral para erros de especificação que podem ter diversas origens, como variáveis independentes omitidas, forma funcional incorreta, erros de medida em variáveis, erros de simultaneidade e inclusão de valores defasados da variável dependente quando os resíduos têm correlação serial. A hipótese nula do teste estabelece que o modelo está corretamente especificado. 
Outro ponto importante nos modelos lineares generalizados é a identificação de possíveis casos influentes. Além de resíduos estudentizados com valores, em módulo acima de 3 , outras técnicas para a identificação destes casos são a alavancagem, DFbetas, DFfit e distância de Cook. Neste trabalho utilizouse, como critério principal, a distância de Cook (Cook,1979), a qual é uma medida da influência de uma dada observação no modelo. $\mathrm{Na}$ análise gráfica, casos com grande distância de Cook em relação aos demais devem ser checados para validação do modelo.

Para avaliação da significância dos parâmetros estimados do modelo linear generalizado uma das alternativas é o teste de Wald (WALD, 1943). O Teste de Wald é obtido por comparação entre a estimativa de máxima verossimilhança do parâmetro estimado e a estimativa de seu erro padrão. A estatística de Wald, possui sob hipótese nula, distribuição assintótica qui-quadrado com $p$ graus de liberdade, sendo $p$ o número de parâmetros a serem testados. Para facilitar a interpretação dos coeficientes estimados, pode-se utilizar a razão de chances, também conhecida como odds ratio. Esta medida compara a probabilidade de sucesso com a probabilidade de fracasso, sendo obtida a partir da comparação de dois valores distintos da variável explicativa.

\section{Definição das Variáveis dos MLGs}

Para atingir o objetivo proposto neste trabalho, foram estimados dois modelos lineares generalizados. O primeiro modelo tem como variável resposta "endividados" e o segundo, a variável "poupadores". Assim, definiu-se a dummy endividados ( $0=$ gasto igual ganho e $1=$ gasto mais que ganho) e a dummy poupadores ( $0=$ gasto igual ganho e 1 gasto menos que ganho). Conforme definido anteriormente, utiliza-se em cada modelo a pressuposição de que tais variáveis apresentam função de distribuição binomial.

Para a construção das variáveis explicativas, as seguintes variáveis do instrumento, foram recodificadas em variáveis binárias: dummy gênero $(0=$ masculino e $1=$ feminino $)$, dummy estado civil $(0=$ casado e 1 = solteiro/viúvo/separado), dummy dependentes ( 0 = não possui e 1 = possui), dummy moradia $\left(0=\right.$ própria e 1 = alugada/financiada), dummy escolaridade de $1^{\mathrm{a}}$ a $4^{\mathrm{a}}$ série, dummy escolaridade de $5^{\mathrm{a}}$ a $8^{\mathrm{a}}$ série, dummy escolaridade ensino médio, dummy escolaridade faculdade, dummy escolaridade pósgraduação, dummy renda de $R \$ 1.000,01$ à $R \$ 3.000,00$, dummy renda de $R \$ 3.000,01$ à $R \$ 5.000,00$, dummy renda de $\mathrm{R} \$ 5.000,01$ a $\mathrm{R} \$ 7.000,00$ e dummy renda acima de $\mathrm{R} \$ 7.000,01$ (para todas as dummys escolaridade e renda, zero corresponde a outras classes e um a classe correspondente), dummy possuir dívida ( 0 = ausência de dívida e 1 = presença), dummy cartão de crédito $(0=$ não possui cartão de crédito $e$ 1 = possui), dummy carnê de loja $(0$ = não possui carnê de loja e $1=$ possui $)$, dummy poupança $(0$ = não possui poupança e 1 = possui poupança $)$, dummy cadastro negativo ( 0 = não tem o nome vinculado a um cadastro negativo e $1=$ tem o nome vinculado a um cadastro negativo), dummy empréstimo do nome $(0=$ não está emprestando o nome e 1 = está emprestando o nome), dummy conta bancária ( 0 = não possui conta bancária e 1 = possui conta bancária) e dummy controle de gastos ( 0 = não controla e 1 = controla).

Assim, ambos os modelos estimados, eram construídos inicialmente sobre a mesmas pressuposições: (i) função de distribuição bernoulli, (ii) mesma matriz de covariáveis, e (iii) função de ligação logit. A única diferença entre os dois, é na construção da variável resposta, que no modelo 1 é "endividados" e no modelo 2 é "poupadores". 


\section{ANÁLISE DOS RESULTADOS}

O primeiro modelo linear generalizado da família binomial foi estimado tendo como variável resposta "endividados", como matriz de covariáveis as especificadas anteriormente e função de ligação logit. A estimação foi realizada por máxima verossimilhança e utilizando o método stepwise (Hocking, 1976), com critério de seleção o AIC. O software R (2017) foi utilizado para todas as estimações. Incialmente avaliou-se o gráfico dos resíduos componente do desvio, o gráfico do envelope simulado, da alavancagem e da distância de Cook (Figura 1).

Figura 1 - Gráficos dos resíduos componentes do desvio, envelope simulado, alavancagem e distância de Cook - modelo 1

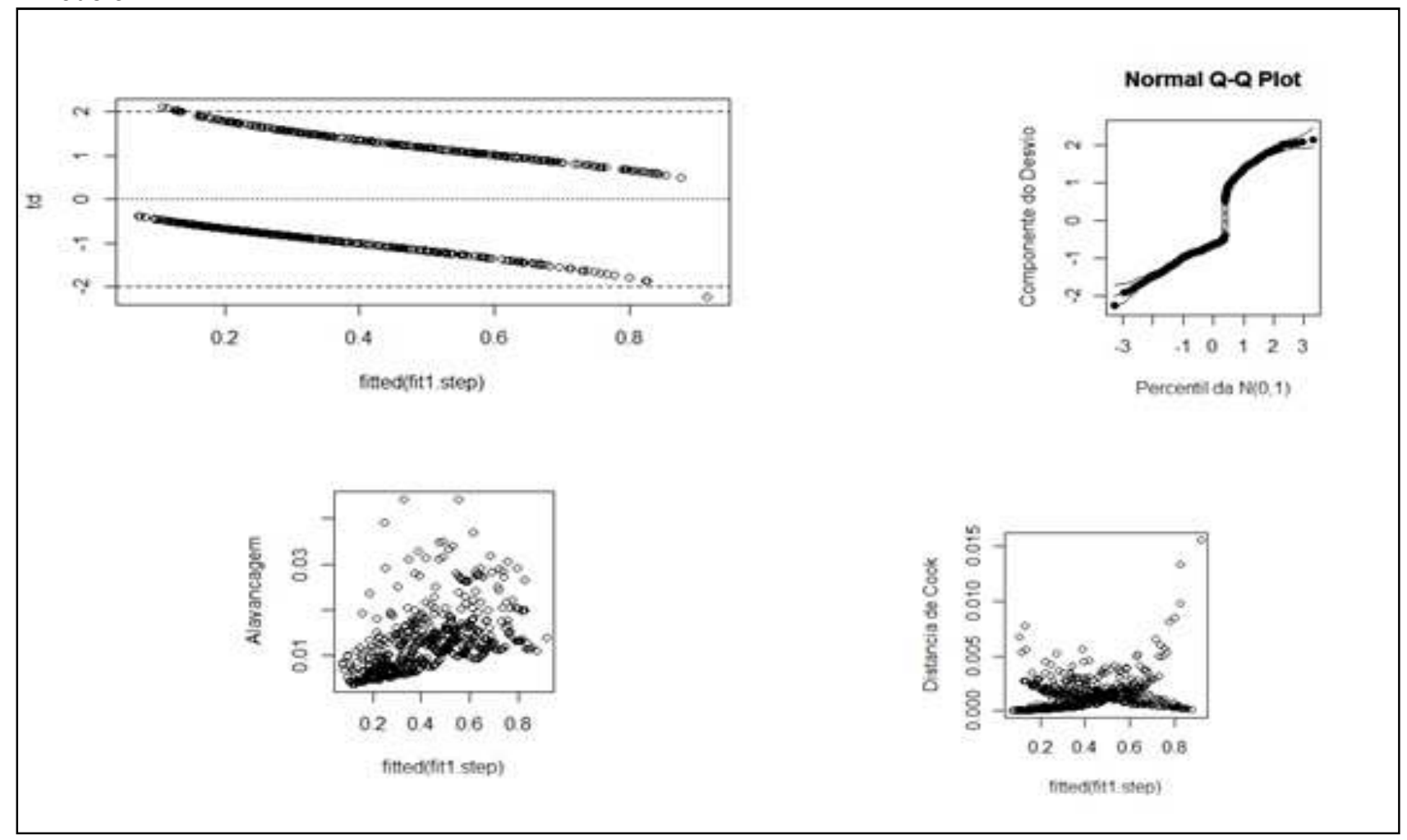

Fonte: elaborado pelos autores (2017)

O envelope não apresenta nenhum caso fora dos limites. No entanto, especialmente a partir do componente do desvio, do gráfico da distância de Cook e alavancagem observa-se a presença de três pontos como possivelmente influentes. Assim o modelo foi novamente estimado, retirando-se estes três pontos. Tal procedimento, implicou na melhora do pseudo $\mathrm{R}^{2}$, além de alterar a significância de alguns coeficientes do modelo estimado. Assim, optou-se pela retirada dos três casos da base de dados. A Figura 2, apresenta os novos gráficos para o modelo estimado sem os outliers. 
Figura 2- Gráficos dos resíduos componentes do desvio, envelope simulado, alavancagem e distância de Cook - modelo inicial sem outliers

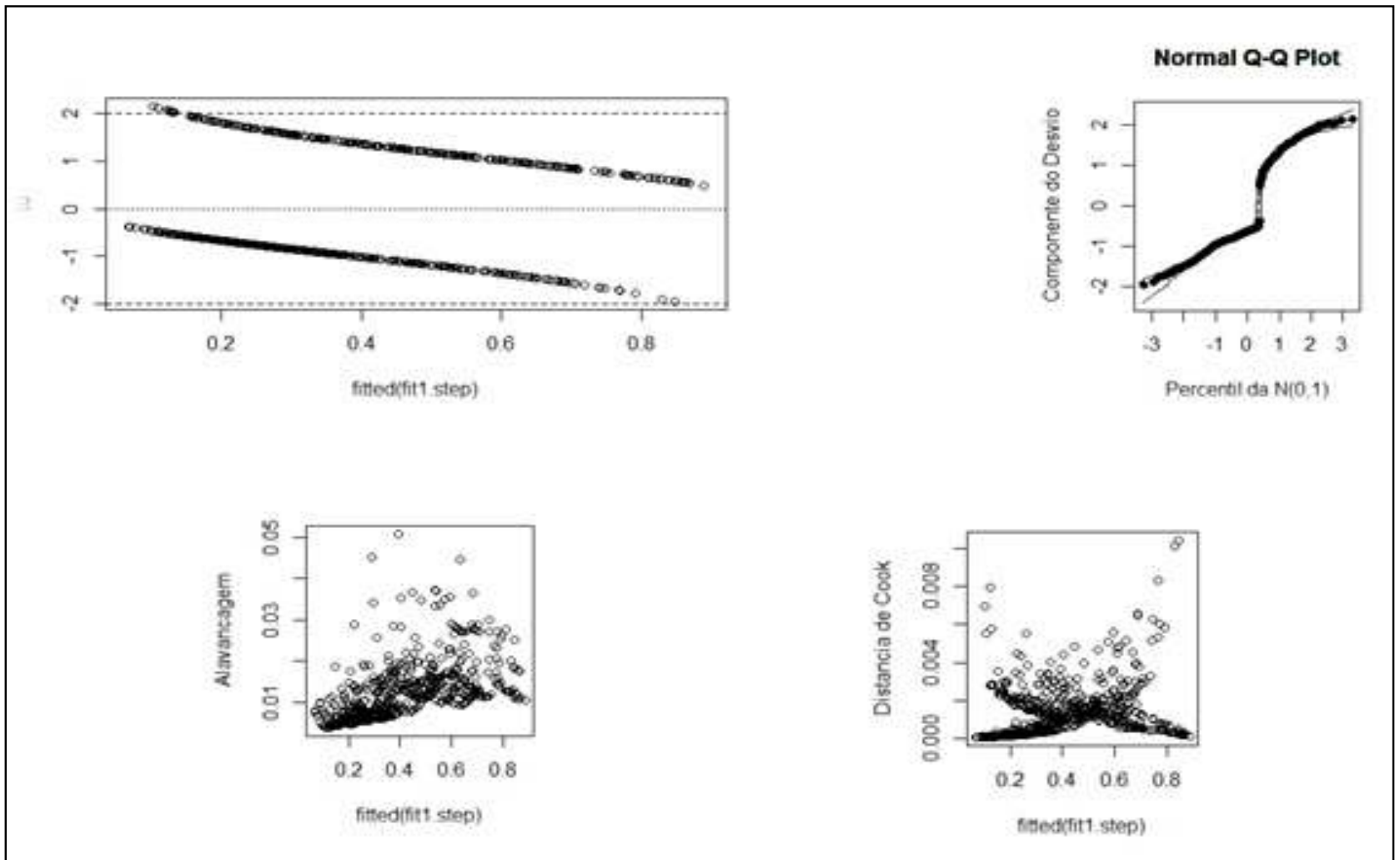

Fonte: elaborado pelos autores (2017)

Observa-se que houve uma redução considerável nos valores da distância de Cook. Inicialmente os pontos mais influentes apresentavam distância em torno de 0,015. Após a retirada dos outliers, os pontos mais distantes estão em torno de 0,010 . Também não se identifica mais pontos com componentes do desvio superiores a -2 .

O envelope simulado não apresenta pontos fora dos limites sendo um indicativo de ajuste do modelo. Ainda para confirmação do ajuste do modelo, aplicou-se o teste Reset de Ramsey (1969), sob a hipótese nula de que o modelo é adequado. A significância do coeficiente ( $p$-valor=0,850), leva a não rejeição da hipótese nula e indica que o modelo está corretamente especificado. Assim, a Tabela 1 apresenta os parâmetros estimados, seus erros-padrões bem como valor e significância do teste de hipótese.

Tabela 1: Coeficientes, erros padrões, valor de Z e significância do Modelo 1 sem outliers

\begin{tabular}{|c|c|c|c|c|}
\hline \multirow{2}{*}{ Variáveis } & \multirow{2}{*}{ Coeficiente } & \multirow{2}{*}{ Erro padrão } & \multicolumn{2}{|c|}{$\mathbf{Z}$} \\
\hline & & & Valor & Sig. \\
\hline Intercepto & 0,904 & 0,358 & 2,524 & 0,012 \\
\hline Idade & $-0,016$ & 0,008 & $-2,054$ & 0,040 \\
\hline Dummy Poupança & -0.708 & 0,167 & $-4,246$ & $2,18 e^{-05}$ \\
\hline Dummy Cadastro Negativo & 0,714 & 0,185 & 3,850 & 0,000 \\
\hline Dummy Conta Bancária & $-0,391$ & 0,204 & $-1,919$ & 0,055 \\
\hline Dummy Controle de Gastos & $-1,040$ & 0,226 & $-4,599$ & $4,24 \mathrm{e}^{-06}$ \\
\hline Dummy Dependentes & 0,638 & 0,182 & 3,498 & 0,000 \\
\hline Dummy Moradia & 0,234 & 0,147 & 1,592 & 0,111 \\
\hline Dummy Escolaridade de $1^{\mathrm{a}}$ a $4^{\mathrm{a}}$ série & 0,503 & 0,346 & 1,451 & 0,147 \\
\hline Dummy Escolaridade Ensino Médio & $-0,311$ & 0,150 & $-2,069$ & 0,039 \\
\hline
\end{tabular}

Fonte: elaborada pelos autores (2017) 
O modelo apresenta nove variáveis, sendo seis com significância menor do que $5 \%$. Para as variáveis dummy, a razão de chances é obtida diretamente pelo cálculo da exponencial do coeficiente. Assim pode-se concluir que manter conta poupança e manter controle dos gastos impacta negativamente na probabilidade de ser "endividado". Esse resultado confirma que um planejamento orçamentário adequado impacta negativamente sobre a probabilidade de ser um endividado (PHAM, YAP \& DOWLING, 2012; MENDES-DASILVA, NAKAMURA \& MORAES 2012; XIAO et al. 2011).

Sendo a redução proporcionada pela conta poupança $(50,73 \%)$ e pelo controle dos gastos $(64,65 \%)$ superiores à de possuir ensino médio (26,70\%). A idade também reduz a probabilidade, mas em um percentual bem menor, sendo que o aumento de um ano implica na redução de 1,50\% na probabilidade do indivíduo ser "endividado". Esses resultados vão ao encontro de outros trabalhos que destacam que a idade tem influência na propensão para um menor endividamento, ou seja, quanto maior a idade menor a probabilidade de ser um endividado (FURNHAM, 1984; WORTHY, JONKMAN \& BLINN ZUCKERMAN \& KUHLMAN, 2000; PANCHIO, 2006; VIEIRA, FLORES \& CAMPARA, 2014, PIKE, 2010; FLORES, 2012; POTRICH et al., 2016). Nessa mesma linha, outros autores complementam afirmando que as pessoas com menor faixa etária apresentam uma maior tendência a terem dividas (TAN, YEN \& LOKE, 2011; KEESE, 2012) Por outro lado, ter cadastro negativo e possuir dependentes implicam em aumentos de 104,26\%, 89,27\% respectivamente, na probabilidade de ser "endividado".

O modelo apresentou um pseudo $\mathrm{R}^{2}$ de Nagelkerke de 19,31\%. Após a análise deste modelo tendo como variável dependente "endividados", passou-se à análise do modelo para os "poupadores", denominado modelo 2. Diferentemente do modelo 1 , neste caso a retirada dos possíveis valores influentes não possibilitou melhora importante em nenhum indicador de ajuste do modelo, por esta razão são apresentados os resultados do modelo 2, com todos os casos amostrais.

Figura 3 - Gráficos dos resíduos componentes do desvio, envelope simulado, alavancagem e distância de Cook - modelo 2
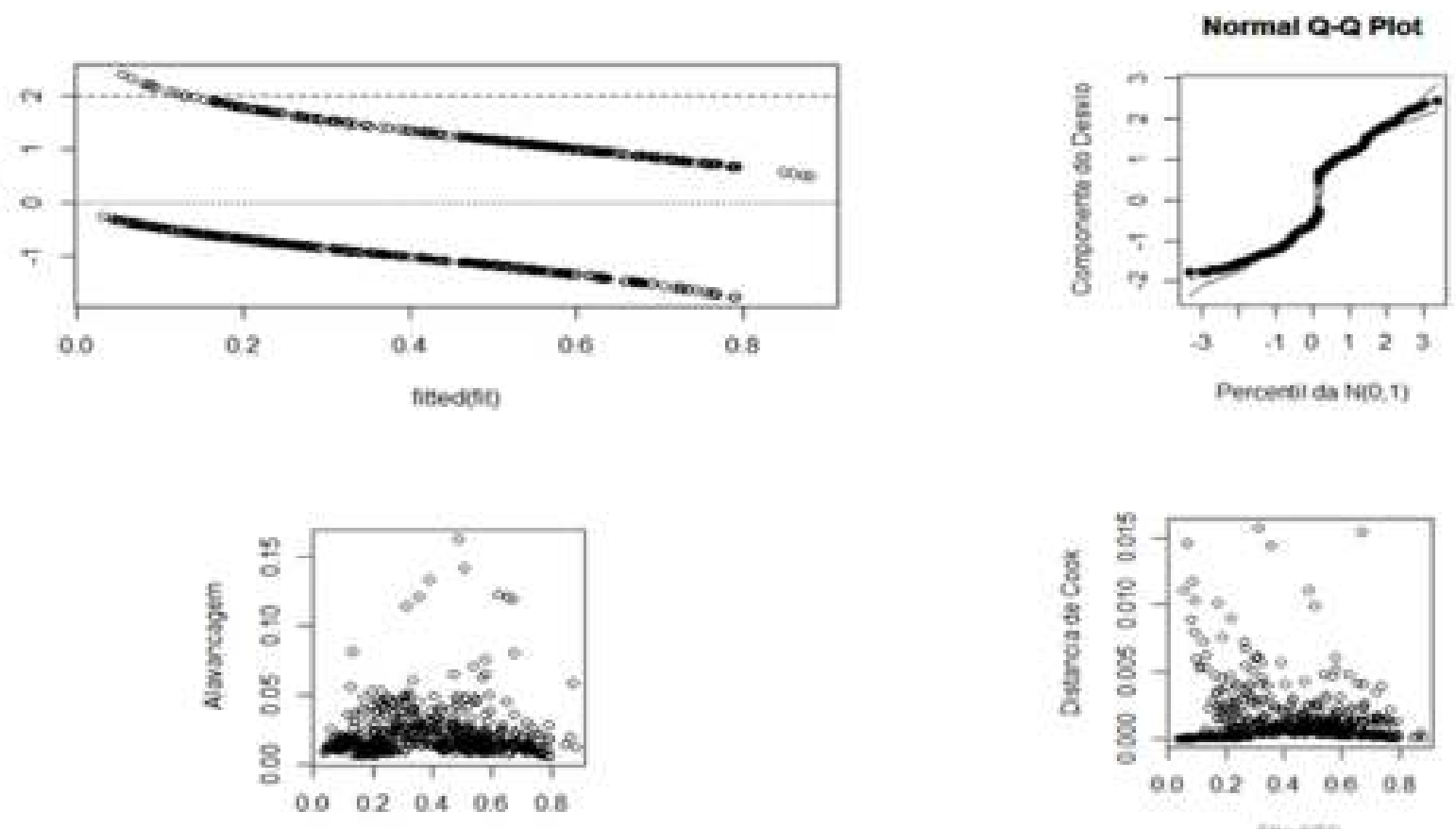

Fonte: elaborado pelos autores (2017) 
No envelope simulado não se observa nenhum valor fora dos limites. Nos componentes do desvio apenas alguns casos acima do valor 2. Na alavancagem e na distância de Cook, alguns valores se apresentam mais dispersos, entretanto não foram considerados influentes já que não alteraram de maneira importante nenhuma estimativa dos coeficientes nem nos indicadores de ajuste do modelo. Assim, obteve-se o seguinte modelo estimado (Tabela 2).

Tabela 2: Coeficientes, erros padrões, valor de Z e significância do Modelo 2 (Poupadores)

\begin{tabular}{lcccc}
\hline \multicolumn{1}{c}{ Variáveis } & Coeficiente & Erro padrão & \multicolumn{2}{c}{ Z } \\
\cline { 3 - 5 } & $-0,942$ & 0,489 & $-1,926$ & 0,054 \\
\hline Intercepto & 1,478 & 0,155 & 9,562 & $2 \mathrm{e}^{16}$ \\
Poupança & $-0,653$ & 0,296 & $-2,206$ & 0,027 \\
Dummy Cadastro Negativo & $-0,840$ & 0,361 & $-2,325$ & 0,020 \\
Dummy Empréstimo do Nome & $-0,402$ & 0,258 & $-1,559$ & 0,119 \\
Dummy Conta Bancária & 1,128 & 0,404 & 2,791 & 0,005 \\
Dummy Controle de Gastos & $-0,266$ & 0,158 & $-1,684$ & 0,092 \\
Dummy Renda 1 & 0,753 & 0,176 & 4,277 & $1,89 e^{-05}$ \\
Dummy Renda 4 & $-0,276$ & 0,137 & $-2,008$ & 0,045 \\
Dummy Gênero & $-0,845$ & 0,505 & $-1,672$ & 0,094 \\
Dummy Escolaridade de 1 ${ }^{a}$ a 4 ${ }^{a}$ série & $-0,793$ & 0,263 & $-3,011$ & 0,003 \\
Dummy Escolaridade Ensino Médio & $-0,918$ & 0,278 & $-3,304$ & 0,001 \\
Dummy Escolaridade Faculdade & $-0,988$ & 0,314 & $-3,144$ & 0,002 \\
Dummy Escolaridade Pós-Graduação & & &
\end{tabular}

Fonte: elaborada pelos autores (2017)

A Tabela 2 indica nove variáveis com nível de significância inferior a $5 \%$, sendo três com impacto positivo na probabilidade de ser "poupador", ou seja, indivíduos que possuem conta poupança, mantêm controle de gastos e auferem renda acima de $\mathrm{R} \$ 7.000,01$ são mais prováveis de gastar menos do que ganham. Retificando essa perspectiva Campara, Vieira e Ceretta (2016), afirmam que as pessoas que se preocupam com poupança e gestão eficiente, tem menor probabilidade a ter atitudes ao endividamento. Por outro lado, ter cadastro negativo, emprestar o nome, ser do gênero feminino e com escolaridade ensino médio, faculdade e pós-graduação são características que diminuem probabilidade de ser "poupador". Dentre todas estas variáveis, as de maior impacto positivo são dummy poupança $(338 \%)$ e manter controle dos gastos (209\%) e as de maior impacto negativo são escolaridade pós-graduação $(63 \%)$ e escolaridade faculdade (60\%). Esse resultado de maior impacto negativo vai ao encontro da pesquisa de Miotto (2013).

Especificamente quanto ao grande impacto da dummy poupança, nota-se que o fato de o indivíduo ter uma conta de poupança numa instituição financeira é um importante indicativo da possibilidade de do indivíduo conseguir gastar menos do que ganha. Esse resultado corrobora com os de Campara, Vieira e Ceretta (2016), os quais elucidaram que os indivíduos que se preocupam com poupança, são menos propensos a serem endividados. Já no modelo anterior, observou-se que o fato do indivíduo manter uma conta poupança aberta reduz a probabilidade de ser um "endividado". Tais resultados são condizentes com o fato de ser a poupança o instrumento financeiro de investimento mais popular no Brasil, sendo, portanto, a primeira alternativa quando as pessoas pensam em investir. 


\section{CONSIDERAÇÕES FINAIS}

Este estudo teve por objetivo construir dois modelos para identificação da probabilidade dos indivíduos serem "poupadores" ou "endividados" a partir das questões relativas ao gerenciamento financeiro e das suas características sociodemográficas. Visando atingir o objetivo proposto, optou-se por realizar um estudo quantitativo de cunho descritivo, através de uma survey.

Os testes iniciais de ajuste do modelo, especialmente através da análise gráfica do envelope simulado, indicaram a adequação da escolha dos parâmetros dos MLGs, especialmente quanto à definição da função de distribuição binomial e da função de ligação logarítimica.

Os possíveis casos influentes, identificados pelos gráficos de resíduos, alavancagem e distância de Cook, mostraram-se realmente impactantes para o modelo 1, o que levou a opção pela retirada dos mesmos, já no modelo 2, não tiveram efeitos importantes na estimação e foram mantidos na modelagem. Tais resultados confirmam a necessidade de que na aplicação da técnica de MLG, a decisão da retirada dos casos influentes não seja baseada apenas na identificação gráfica dos outliers, mas sim na comparação dos resultados dos modelos estimados com e sem os casos identificados na análise gráfica.

Os dois modelos apresentaram valores de pseudo $\mathrm{R}^{2}$ de $19 \%$ e $23 \%$ respectivamente, e o segundo modelo apresentou teste Reset significativo. De certo modo, já era esperado que os valores não fossem relativamente altos para o pseudo $\mathrm{R}^{2}$ e que o teste Reset pudesse indicar algum problema de especificação do modelo, dado que existem evidências na literatura da existência de outros fatores comportamentais, como o materialismo e as compras compulsivas, que impactam no endividamento e na poupança, mas não foram objeto de estudo neste trabalho.

O foco deste estudo foi em variáveis sociodemográficas e variáveis de gerenciamento financeiro facilmente obtidas por gerentes de instituições financeiras e que podem ser inseridas em modelos de concessão de crédito. A ideia principal foi identificar a influência de variáveis de fácil acesso pelos gestores na probabilidade de o indivíduo tornar-se "endividado" ou ser um "poupador". Não se descarta aqui a importância de outros fatores comportamentais, apenas buscou-se avaliar a possibilidade de construção de modelos que auxiliem os gestores nas decisões de concessão de crédito, oferta de produtos para determinados clientes, mas sem a necessidade de utilização de entrevistas ou questionários para a identificação dos fatores comportamentais. Neste sentido, os modelos lineares estimados, cumpriram o papel de indicar diversas variáveis de fácil acesso pelo gestor, que podem sim contribuir para o entendimento do perfil "poupador" ou "endividado", dos seus clientes atuais e potenciais.

Outro aspecto importante dos resultados do modelo estimado, é que as variáveis que se mantiveram no modelo após a estimação por stepwise (cite), apresentaram comportamento, ou seja, impacto na variável resposta condizente com a maioria das evidências empíricas apresentadas nos trabalhos sobre a temática. Portanto, pode-se concluir que dentre as covariáveis escolhidas, várias se mostraram importantes e com o efeito esperado.

Num cenário de crise econômica como o atual, cresce a importância de utilização de modelos desta natureza. O aumento do nível de desemprego tente a levar indivíduos que tinham um perfil de "poupadores" para o grupo de "endividados". Assim, tende a crescer este grupo na economia como um todo, e cabe ao sistema financeiro, desenvolver modelos de concessão de crédito e avaliação de comportamentos de risco financeiro dos seus clientes para evitar o crescimento descontrolado da inadimplência. 


\section{REFERÊNCIAS}

AKAIKE, H. A new look at the statistical model identification. IEEE Transactions on Automatic Control, v.19, n.6, p.716723, 1974.

ATKINSON, A. C. Plots, transformations, and regression: an introduction to graphical methods of diagnostic regression analysis. Clarendon Press, 1985.

BRASIL. Ministério do Desenvolvimento Social e Combate à Fome. Secretaria Nacional de Renda e Cidadania. Programa de Gestão do PBF. Brasília: Ministério do Desenvolvimento Social e Combate à Fome, 2009. Disponível em: <http://www.mds.gov.br/bolsafamilia/capacitacao/arquivos/apostilas/um-panorama-da-gestao-do-bolsa-familia.pdf/view>. Acesso em: 20/04/2016.

BRICKER, J.; KENNICKELL, A. B.; MOORE, K. B.; SABELHAUS, J. Changes in U.S. family finances from 2007 to 2010 : evidence from the Survey of Consumer Finances. Federal Reserve Bulletin, v. 98, n. 2, p. 1-80, 2012.

CAMPARA, J. P. Beneficiários do Programa Bolsa Família: uma análise sob a óptica comportamental e financeira em municípios gaúchos. 2016. 184 f. Dissertação (Mestrado em Administração) - Universidade Federal de Santa Maria, Santa Maria, 2016

CAMPARA, VIEIRA, CERETTA. Entendendo a atitude ao endividamento: fatores comportamentais e variáveis socioeconômicas o determinam? RECADM, v. 15, n. 1, p. 5-24, Jan-Abr/2016.

CARVALHO, A. A.; ALVES, J. E. D. As relações entre o consumo das famílias brasileiras, ciclo de vida e gênero. In: XVII Encontro Nacional de Estudos Populacionais, ABEP, 2010, Caxambú/MG.

CENCI, J. J.; PEREIRA, I.; BARICHELLO, R. Educação financeira, planejamento familiar e orçamento doméstico: um estudo de caso. Tecnológica, v. 3, n. 2, p. 89-104, 2015.

CNC. Confederação Nacional do Comércio de Bens, Serviços e Turismo. Pesquisa nacional de endividamento e inadimplência do consumidor (Peic) - março 2016, 2016. Disponível em: <http://www.cnc.org.br/central-doconhecimento/pesquisas/pesquisa-nacional-de-endividamento-e-inadimplencia-do-consumidor>. Acesso em: 04 abr. 2016.

COOK, R. D.; WEISBERG, S. Residuals and Influence in Regression. New York: Chapman and Hall. 1982.

COOK, R. Dennis. Influential Observations in Linear Regression. Journal of the American Statistical Association American Statistical Association [S.I.] 74 (365): 169-174, 1979.

CORDEIRO, G. M., DEMÉTRIO, C. G. B. Modelos lineares generalizados. In: Minicurso para o $12^{\circ}$ SEAGRO e a $52^{\circ}$ Reunião Anual da RBRAS. UFSM, Santa Maria, RS, julho, 2007.

DINIZ, A. P. C. et al. Influência das variáveis socioeconômicas e demográficas no Bem-estar Financeiro: um estudo do comportamento maranhense. Revista Uniabeu, v. 7, n. 17, p. 218-234, 2014.

DEMÉTRIO, C. G. B.; HINDE, J. Half-normal plots and overdispersion. GLIM newsletter, v. 27, p. 19-26, 1997.

DISNEY, R.; GATHERGOOD, J. Financial literacy and indebtedness: new evidence for UK consumers. In: EconPapers, 2011. Disponível em: <http://speculum-dianae.nottingham.ac.uk/cfcm/documents/papers/11-05.pdf>. Acesso em: 25 mai. 2017.

FEE - Fundação de Economia e Estatística do Estado do Rio Grande do Sul (2013). Disponível em: www.fee.tche.br. Acesso em 05/09/2014.

FERNANDES, A. H. de S.; CANDIDO, J. G. Educação Financeira e nível do endividamento: Relato de pesquisa entre os estudantes de uma instituição de ensino da cidade de São Paulo. Revista Eletrônica Gestão e Serviços, São Paulo, v. 5 n. 2, jul./dez. 2014.

FLORES, S. A. M. Modelagem de equações estruturais aplicada à propensão ao endividamento: uma análise de fatores comportamentais. 2012. 192 f. Dissertação (Mestrado em Administração) - Universidade Federal de Santa Maria, 2012.

FRADE, C. et al. Um perfil dos sobreendividados em Portugal. Portugal: entro de Estudos Sociais. Faculdade de Economia de Coimbra, 2008.

FURNHAM, A. "Many sides of the coin: the psychology of money usage". Personality and Individual Difference. n. 5, 1984, p. 501-9.

GATHERGOOD, J. Self-control, financial literacy and consumer over-indebtedness. Journal of Economic Psychology, v. 33, n. 3, p. 590-602, 2012.

HOCKING, R. R. . A Biometrics Invited Paper. The Analysis and Selection of Variables in Linear Regression Biometrics Vol. 32, No. 1 (Mar., 1976), pp. 1-49

INSTITUTO BRASILEIRO DE GEOGRAFIA E ESTATíSTICA (IBGE, 2010). Censo 2010. Disponível em: <http://www.ibge.gov.br/home/estatistica/populacao/censo2000/>. Acesso em: 23 nov. 2015. 
KEESE, M.; SCHMITZ, H. Broke, ill, and obese: The effect of household debt on health. In: Social Science Research Network. 2011. Disponível em: <http://papers.ssrn.com/sol3/papers.cfm?abstract_id=1750216>. Acesso em: 26 mai. 2017

KEESE, M. Who feels constrained by high debt burdens? Subjective vs. objective measures of household debt. Journal of Economic Psychology, v. 33, n. 1, p. 125-141, 2012.

KUNKEL, F. I. R.; VIEIRA, K. M.; POTRICH, A. C. G. Causas e consequências da dívida no cartão de crédito: uma análise multifatores. Revista Administração. São Paulo, Jun 2015, vol.50, no.2, p.169-182.

LOIOLA, L. D. P. O estresse financeiro em dois grupos de profissionais brasileiros. 2014. 54 f. Dissertação (Mestrado em Administração de Empresas) - Fundação Getulio Vargas, São Paulo, 2014.

LUCENA, W. G. L.; MARINHO, R. A. L. Competências financeiras: uma análise das decisões financeiras dos discentes no tocante as finanças pessoais. In: XVI SEMINÁRIOS EM ADMINISTRAÇÃO, 2013, São Paulo. Anais... São Paulo: XVI SEMEAD FEA-USP, 2013.

LUSARDI, A.; TUFANO, P. Debt Literacy, Financial Experiences, and Overindebtedness. In: National Bureau of Economic Research, Cambridge, 2009. Disponível em: <http://www.nber.org/papers/w14808.pdf>. Acesso em: 27 maio. 2017.

MIOTTO, Ana Paula Santos Cruz; PARENTE, Juracy. Antecedentes e consequências da gestão das finanças domésticas: uma investigação com consumidores da classe. Tese (Doutorado) - Fundação Getúlio Vargas, São Paulo, 2013.

MEDEIROS, G. M. de et al.. Endividamento e literacia financeira na perspectiva dos consumidores endividados no cartão de crédito. In: XXXVIII EnANPAD - Encontro da ANPAD, Rio de Janeiro, RJ, 2014.

MENDES-DA-SILVA, W.; NAKAMURA, W. T.; MORAES, D. C. Credit card risk behavior on college campuses: evidence from Brazil. BAR Brazilian Administration Review, v. 9, p. 351-373, 2012.

MCCULLAGH, P. and NELDER, J. A.- Generalized Linear Models, Chapman and Hall, London, Second Edition. 1989.

MOURA, A. Impacto dos Diferentes Níveis de Materialismo na Atitude ao Endividamento e no Nível de Dívida para Financiamento do Consumo nas Famílias de Baixa Renda do Município de São Paulo. 2005. 176 f. Dissertação (Mestrado em Administração de Empresas)- Fundação Getulio Vargas, São Paulo, 2005.

MULLER, K. O. Sociedade de consumo e cultura do endividamento: estudo de caso sobre compradores compulsivos em Porto Alegre, RS. Trabalho de conclusão de curso (Graduação em Ciências Sociais)- Universidade Federal do Rio Grande do Sul, Porto Alegre, 2010.

MUNDY, S. Financial Education Programmes in Schools: Analysis of Selected Current Programmes and Literature - Draft recommendations for best practices. OECD. Mimeo. 2011.

NAGELKERKE, N. J. D. A note on a general definition of the coeficient of determination. Biometrika 78 (3), $691-692,1991$.

ORGANIZATION FOR ECONOMIC CO-OPERATION AND DEVELOPMENT. Financial literacy and inclusion: Results of OECD/INFE survey across countries and by gender. OECD Publishing, (OECD, 2013). Disponível em: <http://www.oecd.org/daf/fin/financialeducation/TrustFund2013_OECD_INFE_Fin_Lit_and_Incl_SurveyResults_by_Coun try_and_Gender.pdf >. Acesso em: 15 abr. 2017.

PAULA, G. A. Modelos de Regressão com apoio computacional. Instituto de Matemática de São Paulo - Universidade de São Paulo, 2013.

PHAN, T. H., YAP, K., \& DOWLING, N. A. The impact of financial management practices and financial attitudes on the relationship between materialism and compulsive buying. Journal of Economic Psychology, 33(3), 461-470, 2012.

PLAGNOL, A. C. Financial satisfaction over the life course: the influence of assets and liabilities. Journal of Economic Psychology, v.32, p. 45-64, 2011.

$\mathrm{PONCHIO}, \mathrm{M}$. C. The Influence of Materialism on Consumption Indebtedness in the Context of Low Income Consumers From the City of Sao Paulo. 2006. 175 p. Tese (Doutorado em Administração)- Fundação Getúlio Vargas, São Paulo, 2006.

POTRICH, G. et al. Modelando a propensão ao endividamento: os fatores comportamentais e socioeconômicos são determinantes? Revista Facultad de Ciencias Económicas: Investigación y Reflexión, vol. XXIV, núm. 2, 2016, pp. 85110, Universidad Militar Nueva Granada, Bogotá, Colômbia.

PORTER, N. M.; GARMAN, E. T. Testing a conceptual model of financial well-being. Financial Counseling and Planning, v. 4 , p. $135-165,1993$.

RAMSEY, J. B. Tests for specification errors in classical linear least-squares regression analysis. Journal of the Royal Statistical Society. Series B (Methodological), p. 350-371, 1969.

R Core Team. R: A language and environment for statistical computing. R Foundation for Statistical Computing, Vienna, Austria, 2017. Diponível em: <https://www.R-project.org/>. Acesso em: 23/05/2017

SERVIÇO DE PROTEÇÃO AO CRÉDITO (SPC). Análise da educação financeira: dívidas, 2016. Disponível em: <https://www.spcbrasil.org.br/uploads/st_imprensa/analise_educacao_financeira_dividas2.pdf>. Acesso em: 11 abr. 2016. 
SERVIÇO DE PROTEÇÃO AO CRÉDITO (SPC). Análise da educação financeira: habilidades. 2014. Disponível em: $<$ https://www.spcbrasil.org.br/wpimprensa/wp-content/uploads/2016/04/Analise-Educacao-Financeira-Habilidades1.pdf>. Acesso em: 14 abr. 2016.

SILVA, A. F. et al. Finanças pessoais: um estudo sobre a utilização do orçamento pelos alunos graduandos em Ciências Contábeis da FSG. Anais...Seminário de Iniciação Científica de Ciências Contábeis, v. 4, n. 2, p. 361-379, 2014.

SILVA, P. R. Psicologia do risco de crédito: análise da contribuição de variáveis psicológicas em modelos de credit scoring. 2011. 244f. Tese (Doutorado em Administração), Universidade de São Paulo, 2011.

SANTOS, L. R. Mulheres que trabalham fora e mulheres que não trabalham fora: existe diferença no gerenciamento financeiro dos dois grupos? Revista Pensamento Contemporâneo em Administração, v. 4, n. 2, p. 95-107, 2010.

SHOCKEY, S. S. Low-wealth adults financial literacy, money management behavior and associates factors, including critical thinking. 2002. $740 \mathrm{f}$. Thesis, Ohio State University, Utah, 2002.

TAN, A. K. G., YEN, S., \& LOKE, Y. J. Credit card holders, convenience users and revolvers: a tobit model with binary selection and ordinal treatment. Journal of Applied Economics, 14(2), 225-

255, 2011.

TRINDADE, L. L.; RIGHI, M. B.; VIEIRA, K. M. De onde vem o endividamento feminino? Construção e validação de um modelo PLS-PM. Revista Eletrônica de Administração, v. 18, n. 3, p. 718-746, 2012.

VIEIRA, K. M. et al. Níveis de Materialismo e Endividamento: Uma Análise de Fatores Socioeconômicos na Mesorregião Central do Estado no Rio Grande Do Sul. Revista de Administração, Contabilidade e Economia da Fundace, v. 5, n. 2, 2014.

VIEIRA, K. M.; FLORES, S. A. M.; CAMPARA, J. P. Propensão ao Endividamento no Município de Santa Maria (RS): verificando diferenças em variáveis demográficas e culturais. Teoria e Prática em Administração, v. 4, n. 2, p. 180-205, 2015.

VIEIRA, K. M.; OLIVEIRA, M. O. R.; KUNKEL, F. I. R. The Credit Card Use and Debt: Is there a trade-off between compulsive buying and ill-being perception? Journal of Behavioral and Experimental Finance, v. 10, p. 75-87, 2016.

XIAO, J. J., TANG, C., SERIDO, J., \& SHIM, S. Antecedents and consequences of risky credit behavior among college students: application and extension of the theory of planned behavior. Journal of Public Policy \& Marketing, 30(2), 239258, 2011.

WALD, A. Tests of statistical hypothesis concerning several parameters when the number of observations is large. Transactions of the American Mathematical Society 54, 426-482, 1943.

WANG, L.; LU, W.; MALHOTRA, N. K. Demographics, attitude, personality and credit card features correlate with credit card debt: A view from China. Journal of Economic Psychology, v. 32, n. 1, p. 179-193, 2011.

WORTHY, S. L.; JONKMAN, J.; BLINN-PIKE, L.. Sensation-seeking, risk-taking, and problematic financial behaviors of college students. Journal of Family and Economic Issues, v. 31, n. 2, p. 161-170, 2010.

ZUCKERMAN, M. \& KUHLMAN, D. M. Personality and risktaking: Common biosocial factors. Journal of Personality, 68 (6): 999-1029, 2000. 